\title{
QUALIDADE DO LEITE: VISÃO DE PRODUTORES RURAIS DO MUNICÍPIO DE SÃO MARTINHO - RS
}

Fernanda Hammes Stroeher ${ }^{1}$, Bárbara Estevão Clasen², Danni Maísa da Silva², Ramiro Pereira Bisognin², Eduardo Lorensi de Souza², Mastrângello Enívar Lanzanova², Divanilde Guerra², Fernanda Hart Weber²

\begin{abstract}
RESUMO - O leite é um alimento que apresenta uma das mais completas fontes de nutrientes de proteínas, lipídeos, carboidratos, vitaminas e sais minerais. A atividade leiteira apresenta impacto socioeconômico significativo na Região Celeiro do Estado do Rio Grande do Sul, e é um mercado cada vez mais exigente, em relação à qualidade do produto. O maior problema verificado no Rio Grande do Sul e, mais especificamente, na Região alvo deste estudo, foram as ocorrências de fraudes no leite cru. Diante desta problemática, objetivou-se identificar e relatar o ponto de vista de produtores rurais em relação as adulterações em leite praticadas as quais foram investigadas e denunciadas na “Operação Leite Compensado”, pelo Ministério Público Estadual. Para isso, utilizou-se um questionário semiestruturado, direcionado a 20 produtores de leite do município de São MartinhoRS. Constatou-se que a maioria dos produtores tinham preocupação com as fraudes descobertas e declararam apoio as investigações. Tinham também preocupação com a produção e a venda de um produto de boa qualidade, considerando, especialmente, os aspectos relacionados à higiene durante a ordenha, alimentação e à sanidade dos animais.
\end{abstract}

Palavras chave: fraudes, produtor rural, qualidade do leite.

\section{MILK QUALITY: VISION OF RURAL PRODUCERS IN THE MUNICIPALITY OF SÃO MARTINHO, RS, BRAZIL}

\begin{abstract}
Milk is a food that has one of the most complete nutrient sources of protein, lipids, carbohydrates, vitamins and minerals. Milk activity has a significant socioeconomic impact in the Granary Region of the State of Rio Grande do Sul, and is an increasingly demanding market in relation to product quality. The biggest problem in Rio Grande do Sul and, more specifically, in the region targeted by this study, were the occurrences of fraud in raw milk. In view of this problem, the objective was to identify and report the point of view of rural producers regarding the adulterations in milk practiced which were investigated and denounced in the "Operação leite Compensado", by the State Public Ministry. For this, a semi-structured questionnaire was used, directed to 20 milk producers in the municipality of São Martinho-RS. It was found that most producers were concerned about the scams discovered and supported the investigations. They were also concerned about the production and sale of a good quality product, especially considering hygiene aspects during milking, feeding and animal health.
\end{abstract}

Keywords: farmer, fraud, milk quality.

\footnotetext{
${ }^{1}$ Médica Veterinária. Especialista em Segurança Alimentar e Agroecologia pela Universidade Estadual do Rio Grande do Sul - UERGS, Unidade em Três Passos.

${ }^{2}$ Professores da UERGS, Unidade em Três Passos. Endereço para correspondência: Rua Cipriano Barata, nº 47. Bairro Érico Veríssimo - Três Passos. CEP: 98600-000. Contato: (55) 3522-2895. E-mail: fernanda-hart@uergs.edu.br
} 


\section{INTRODUÇÃO}

Entende-se por leite, sem outra especificação, o produto oriundo da ordenha completa e ininterrupta, em condições de higiene, de vacas sadias, bem alimentadas e descansadas (Brasil, 2011). O leite é considerado uma das mais completas fontes de nutrientes como proteínas, lipídeos, vitaminas e sais minerais. A produção leiteira é uma atividade que tem impacto socioeconômico significativo no Brasil (Silva, 2013). De acordo com a Organização das Nações Unidas para Agricultura e Alimentação, o Brasil é a quinto maior produtor de leite mundialmente, atrás apenas da Índia, Estados Unidos e Paquistão (FAO, 2017).

No Brasil, o Estado do Rio Grande do Sul, no ano de 2014 ocupou o segundo lugar entre os estados que mais produzem leite. Ainda no ranking nacional, Minas Gerais ocupa o primeiro lugar e o Estado do Paraná o terceiro sendo que estes três Estados associados são responsáveis por mais da metade da produção brasileira de leite (Jung \& Matte Júnior, 2017).

A produção e o consumo de leite de vaca e derivados têm crescido no Brasil e em muitos países em desenvolvimento (Alves et al., 2016). Desta forma, o mercado tem se apresentado exigência crescente em relação à qualidade do leite (Paixão et al., 2014).

Entretanto, a qualidade do leite consumido no país é uma constante preocupação de profissionais da área como técnicos e autoridades ligadas à área de saúde e laticínios. Um dos grandes entraves relacionados à qualidade do leite é práticas de fraudes as quais causam prejuízos econômicos, como a redução do rendimento industrial, além da possibilidade de causar riscos à saúde dos consumidores (Robim et al., 2012).

No ano de 2014, um posto de resfriamento de leite situado no Município de São Martinho - RS, foi alvo de investigações do Ministério Público Estadual, suspeito de fornecer leite adulterado a uma cooperativa situada em Londrina - PR (Colussi, 2014). Além desta, várias outras indústrias lácteas no Estado do Rio Grande do Sul sofreram investigações, que evidenciaram diversas adulterações cometidas em todo o estado (Colussi, 2014).

Em virtude da preocupação com as fraudes descobertas no estado do RS nos últimos anos, este trabalho teve como objetivo conhecer e analisar o ponto de vista de produtores de leite do município de São
Martinho sobre as fraudes que podem ser cometidas no leite, considerando os possíveis prejuízos, o grau de preocupação em relação a oferta de um produto de qualidade.

\section{MATERIALE MÉTODOS}

A pesquisa foi desenvolvida no Município de São Martinho-RS, cidade situada na Região Celeiro do Estado do Rio Grande do Sul. Sua população é de 5.773 habitantes (IBGE, 2010), tendo como principal fonte de renda a agricultura. As metodologias adotadas incluíram realização de revisão bibliográfica, levantamento prévio do número total de produtores com atuação na atividade leiteira e aplicação de um questionário semiestruturado no segundo semestre de 2016, nos meses de setembro e outubro. De um total de 208 produtores, 20 foram selecionados aleatoriamente e entrevistados, obtendose uma amostra em torno de $1 \%$ do total de produtores de leite do município.

Os questionários foram aplicados e respondidos durante as visitas nas propriedades a apenas um dos membros. Os produtores responderam também perguntas relacionadas ao seu grupo familiar, dimensão das propriedades e da produção leiteira, preocupações em relação à qualidade do leite, saúde dos consumidores e fraudes.

Os dados foram tabulados em Excel e analisados por meio da geração de índices que identificaram os aspectos e a visão dos produtores em relação aos pontos levantados. Em alguns casos, no momento da entrevista os produtores escolheram mais de uma opção, não sendo gerados gráficos e sim tabelas com as porcentagens de entrevistados que haviam escolhido determinada opção.

\section{RESULTADOS E DISCUSSÃO}

Em relação a idade, 25\% dos entrevistados apresentavam de 20 a 30 anos, $15 \%$ de 30 a 40 anos, $25 \%$ de 40 a 50 anos, $30 \%$ de 50 a 60 anos, $5 \%$ dos tinham idade acima de 60 anos e, não havia nenhum entrevistado com menos de 20 anos (Dados não mostrados). Estes resultados demonstram a realidade atual de diversas comunidades rurais do sul do Brasil, onde o número de jovens que decidem assumir a propriedade familiar e exercer a profissão de agricultor é cada vez menor (Anjos \& Caldas, 2015), bem como, o aumento da população idosa, revela um processo 
de envelhecimento e essa configuração populacional pode comprometer a sucessão nos estabelecimentos rurais (Froehlichi et al., 2011).

Dentre as famílias entrevistadas, 45\% delas eram compostas por duas a três pessoas que residem na propriedade, $30 \%$ eram de famílias com quatro a cinco pessoas e apenas $25 \%$ dos entrevistados compunham famílias com mais de seis pessoas. Esse perfil demonstra uma redução no tamanho médio das famílias, e da fecundidade no Brasil, a qual vem ocorrendo de forma sustentada em todos os patamares socioeconômicos (Leone et al., 2010).

O tamanho das propriedades visitadas variou entre 7 a 50 hectares, o que configura os entrevistados como pequenos produtores rurais com base na Lei $n^{\circ}$. 11.428, de 22 de dezembro de 2006 (Brasil, 2006). O pequeno produtor rural é aquele que, reside na zona rural, possui posse de gleba rural não superior a 50 (cinquenta) hectares, explorando-a mediante o trabalho pessoal e de sua família, admitindo-se a ajuda eventual de terceiros.

Apenas $10 \%$ das famílias entrevistadas estava a menos de 5 anos nesse ramo, $5 \%$ estava de 5 a 10 anos, $15 \%$ de 10 a 20 anos, e a maior parte dos entrevistados ou seja $40 \%$ produzia leite entre 20 a 30 anos, e, 30\% dos entrevistados estava na atividade leiteira a mais de 30 anos. A maior parte dos entrevistados estava na atividade a vários anos (Figura 1), diferente

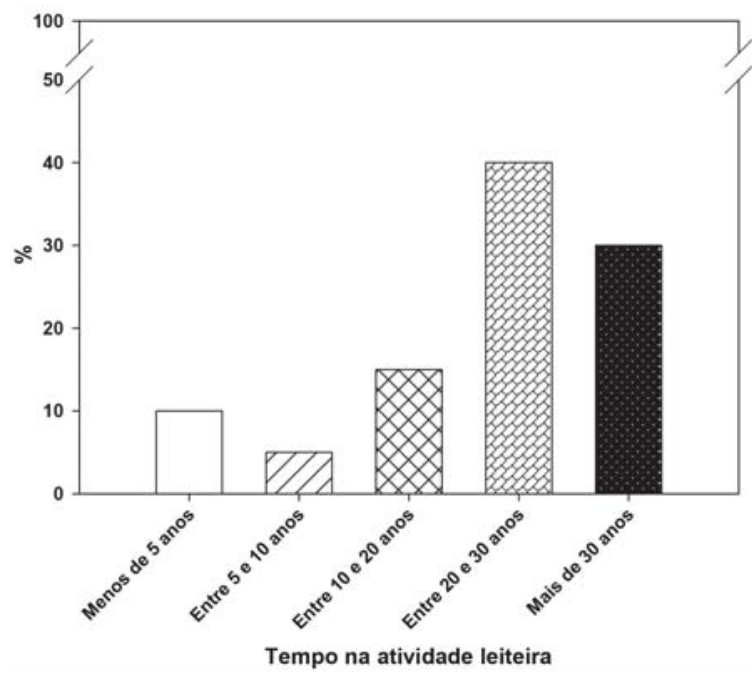

Figura 1 - Tempo de trabalho dos produtores entrevistados sobre atividade leiteira, em São Martinho RS, 2016. do que foi relatado nos estudos de Borsanelli et al. (2015) em que a maioria dos produtores entrevistados, tinham entrado na atividade leiteira a menos de 5 anos.

Sobre a quantidade de leite produzido mensalmente (Figura 2), verificou-se que a maior parte dos entrevistados são pequenos produtores de leite (Sena et al. (2013) com produção abaixo de 20 mil litros de leite ao mês. Embora tenham sido identificados produtores mais tecnificados e especializados, a maioria ainda se encontrava na condição de baixo grau tecnológico. De acordo com Parré et al. (2011) a maioria dos produtores com baixa produtividade do rebanho têm como principal ocupação o trabalho rural, produzem menor volume de leite e estão há mais tempo na atividade leiteira.

Este resultado também foi evidenciado no presente trabalho, pois a maioria dos produtores tem a atividade leiteira como atividade secundária ainda nas propriedades, tendo como atividade principal o cultivo de grãos. Entretanto, este cenário encontrava-se em mudança gradual, considerando que o produtor que possuía 10 a 15 hectares é considerado pequeno produtor de grãos, o que torna, muitas vezes, a atividade inviável mas pode ser um grande produtor de leite utilizandose essa mesma quantidade de área (Medeiros \& Brum, 2016).

Antes da "Operação Leite Compensado", realizada pelo Ministério Público no Estado do Rio Grande do

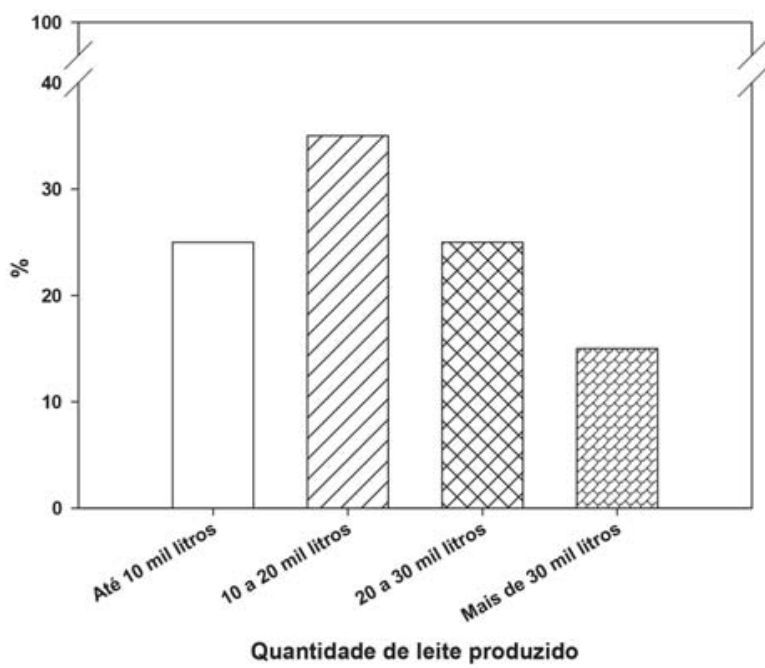

Figura 2 - Volume de leite produzido, mensalmente, nas propriedades dos produtores entrevistados, em São Martinho/RS, 2016. 
Sul, na qual foram investigados transportadores de leite e empresas que adulteravam produtos lácteos, nem todos os produtores acreditavam na ocorrência das fraudes de acordo com o relatado por Zagonel et al. (2016). No presente trabalho, $50 \%$ dos entrevistados acreditavam na veracidade de ocorrência de fraudes no leite (Dados não mostrados).

Quando os entrevistados foram questionados sobre o local de ocorrência das adulterações no produto, relataram que ocorriam na indústria e no transporte, condizente com resultados apresentados por Zagonel et al. (2016) que apontam que na operação leite compensado, transportadores de leite foram presos e que postos de resfriamento e indústrias também estavam envolvidas no esquema de fraudes.

Os resultados sobre a localização de ocorrência das fraudes, na opinião dos produtores rurais estão apresentados na Tabela 1. Dentre os entrevistados, $75 \%$ relataram que acreditavam que a maioria das fraudes ocorriam na indústria, 70\% no transporte do leite e $20 \%$ pelos próprios produtores.

Sobre a confiança dos produtores nas indústrias brasileiras de lácteos $40 \%$ afirmaram confiar, outros $40 \%$ relataram confiar apenas em algumas indústrias e outros $20 \%$ afirmaram que não confiam. Todos os entrevistados acreditavam que as fraudes podem causar problemas à saúde dos consumidores e $80 \%$ dos entrevistados acreditavam que a fraude mais realizada ainda é a adição de água ao leite. A adição de água ao leite é considerada uma das adulterações mais frequentes (Pinheiro, 2015), porém, esse tipo de prática, além de lesar o consumidor, pode colocar em risco a saúde do mesmo. A adição de água é facilmente detectada na indústria por meio da análise da Determinação do Índice Crioscópico ou Depressão do Ponto de Congelamento do Leite (Brasil, 2006). Outras práticas fraudulentas também foram citadas pelos produtores como a adição de uréia, hidróxido de sódio, bicarbonato

Tabela 1 - Local de ocorrência das fraudes de acordo com os entrevistados, em São Martinho/ RS, 2016

\begin{tabular}{lc}
\hline Local & Entrevistados (\%) \\
\hline Indústria & 75 \\
Transportador & 70 \\
Produtor & 20 \\
\hline
\end{tabular}

de sódio e outros produtos químicos que os entrevistados não souberam nomear.

Em relação à preocupação dos produtores com a qualidade do leite que comercializam, 95\% afirmaram que se preocupavam com o problema. Apenas $5 \%$ dos entrevistados não demonstraram preocupação.

Quando questionados se recebiam algum tipo de assistência técnica por meio de visitas de médicos veterinários, zootecnistas e outros profissionais ligados à área, para averiguar a qualidade do leite, $85 \%$ dos entrevistados mencionaram que recebiam, sendo que os outros $15 \%$ afirmaram não obter nenhuma orientação profissional.

Já quando os entrevistados foram questionados sobre o que faziam para obter um produto de qualidade, os resultados estão apresentados na Tabela 2.

Dentre os entrevistados, 95\% responderam ser a higiene o principal fator para se obter um leite de boa qualidade, 35\% mencionaram a alimentação, 20\% a sanidade dos animais e $5 \%$ mencionou o bem-estar animal (BEA). Um percentual de $75 \%$ dos entrevistados não sentiam-se prejudicados com as investigações e, desta forma, aprovaram as investigações do Ministério Público Estadual, entretanto 25\% relataram que se sentiram prejudicados.

As indústrias de laticínios para as quais o leite era fornecido encontram-se apresentadas na Figura 3.

Dentre os entrevistados 25\% comercializavam o leite produzido para a indústria de laticínios Piracanjuba, $25 \%$ para a indústria Lactalis, 15\% para Itambé e 10\% para Nestlé. Foram citadas também outras indústrias as quais associadas correspondiam a $25 \%$ do total.

A maioria dos produtores entrevistados manifestaram confiança em apenas algumas indústrias brasileiras de lácteos ou em nenhuma, resultado condizente com

Tabela 2 - Percentual de adoção de itens de Boas Práticas de Produção de leite nas propriedades para obtenção de leite de boa qualidade, em São Martinho - RS, 2016

\begin{tabular}{lc}
\hline Conduta adotada & Entrevistados (\%) \\
\hline Higiene & 95 \\
Alimentação & 35 \\
Sanidade dos animais & 20 \\
Bem estar animal & 5 \\
\hline
\end{tabular}




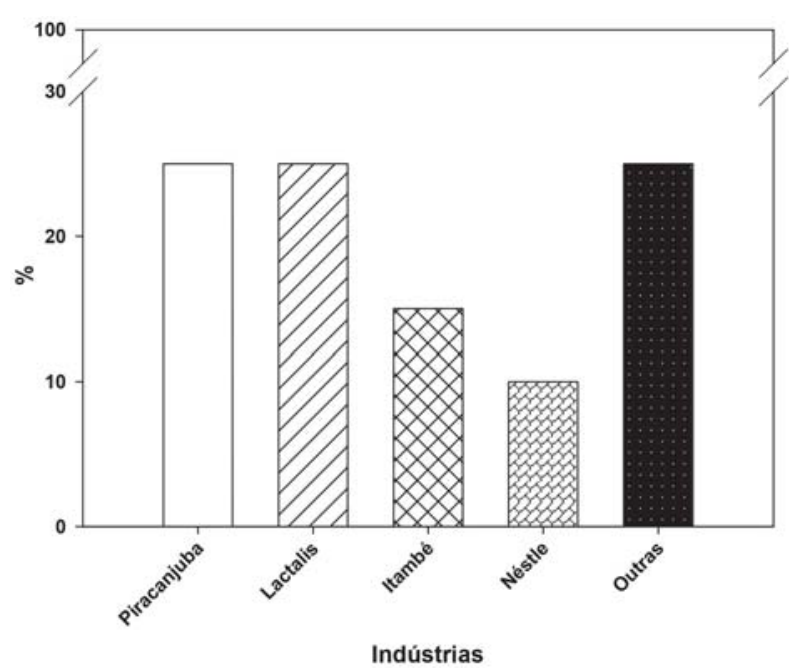

Figura 3 - Indústrias para as quais os entrevistados vendiam o leite produzido em São Martinho -RS, 2016.

a afirmação de Zagonel et al. (2016) que afirmam que a crise na atividade leiteira afetou o conjunto do setor devido ao baixo índice de confiança do consumidor sobre os produtos lácteos e seus derivados.

Os produtores, em sua maioria, afirmaram que se preocupavam com a qualidade do leite que comercializavam, considerando a remuneração do leite pelas empresas pela quantidade e qualidade do produto avaliada por meio de análises físico-químicas (gordura, acidez, alizarol, densidade, proteína, sólidos totais, sólidos desengordurados e índice crioscópico), Contagem Padrão em Placas (CPP), Contagem de Células Somáticas (CCS) e, Pesquisa de Resíduos de Antibióticos (Brasil, 2011; Martins et al., 2015).

Quando questionados sobre a conduta para obtenção de leite de boa qualidade, a maioria dos produtores indicou a higiene como principal pré-requisitos além da alimentação, sanidade do rebanho e bem-estar animal (BEA). Sabe-se que a qualidade do leite está diretamente relacionada à condições de armazenamento, treinamentos técnicos, conscientização e capacitação dos produtores (Corbucci et al., 2015).

Para se obter um produto de boa qualidade é de extrema importância que os animais possuam uma alimentação adequada, acesso a água potável, estejam sadios e em condições de bem-estar adequadas. O local onde é realizada a ordenha, deve estar sempre limpo e devem ser realizados os procedimentos corretos de higiene nos animais antes e após a ordenha. Com o fim da ordenha, todos os equipamentos utilizados, devem ser cuidadosamente lavados e sanitizados, e o leite deve ser imediatamente resfriado a temperatura de $4^{\circ} \mathrm{C}$ em tanques de refrigeração ou a $7^{\circ} \mathrm{C}$ em tanques de refrigeração por imersão. Em ambos os casos essa temperatura deve ser alcançada em no máximo 3 horas após o término da ordenha. O leite pode ser conservado na propriedade, por no máximo 48 horas, até o momento de seu transporte até a indústria. Na recepção do leite, o mesmo passa por análises laboratoriais, onde se verifica se o produto está dentro dos padrões de qualidade exigidos pela empresa, após ocorre a descarga e o processamento do produto (Brasil, 2011).

Alguns produtores afirmaram que se sentiram prejudicados com as investigações, pois comercializavam leite para algumas indústrias que foram investigadas na ação e acabaram não recebendo o pagamento pelo produto já entregue para as mesmas. Muitas empresas reduziram drasticamente o valor pago ao produtor, outras não cumpriram suas obrigações com os produtores rurais, sendo fechadas e enquadradas judicialmente por órgãos fiscalizadores e por credores, entre eles, produtores rurais (Zagonel et al., 2016).

A maioria dos produtores comercializava o leite para as indústrias Piracanjuba, Lactalis, Itambé e Nestlé que, de acordo com o "Ranking Maiores Empresas de Laticínios do Brasil - 2015” (Leite Brasil, 2016) estão entre as 4 maiores indústrias de lácteos do Brasil, na ordem Nestlé, Lactalis, Itambé e Laticínios Bela Vista (Piracanjuba). Esse resultado é demonstrativo de que os produtores optavam pela comercialização do leite para empresas maiores, que se encontravam há mais tempo na atividade leiteira e transmitiam maior confiança e credibilidade ao produtor.

\section{CONCLUSÕES}

Os pequenos produtores em sua maioria na região, poderão ficar sem sucessor em futuro próximo devido ao avanço da idade dos proprietários e a saída do jovem do meio rural.

Em relação às fraudes, os produtores de leite mostraram-se consideravelmente preocupados com as fraudes de leite no estado do Rio Grande do Sul, e apoiam as investigações. Fato que é de fundamental 
importância para a cadeia produtiva de leite, visto que priorizam a produção de leite e derivados com qualidade e para que possam contribuir para a sustentabilidade do setor e para a saúde dos consumidores.

\section{LITERATURA CITADA}

ALVES, E.R.A.; LÍCIO, A.M.A.; CONTINI, E. Perspectivas do Brasil no comércio internacional de lácteos. Capítulo em livro científico (ALICE). Embrapa, 2016. Disponível em:< https://www.alice.cnptia.embrapa.br/alice/ bitstream/doc/1064579/1/PerspectivasdoBrasil.pdf >. Acesso em: 23 de out. 2017.

ANJOS, F.S.; CALDAS, N.V. Ser ou não ser agricultor? Eis a questão. Representações sociais sobre a profissão de agricultor entre jovens de comunidade rural do Sul do Brasil. Revista de Extensão e Estudos Rurais, Viçosa, v.4, n.1, p.14-26, 2015.

BORSANELLI, A.C.; FERRAUDO, A.S.; SAMARA, S.I. et al. Tempo na atividade e percepção de risco de produtores de leite no emprego de produtos veterinários. Veterinária e Zootecnia, v.22, n.1, p.54-60, 2015.

BRASIL. Ministério da Agricultura, Pecuária e Abastecimento. Instrução Normativa $\mathbf{n}^{\circ}$. 62, de 29 de dezembro de 2011. Disponível em: <http://www.apcbrh.com.br/files/ IN62.pdf>. Acesso em: 28 de ago. 2016.

BRASIL. Ministério da Agricultura. Secretaria de Defesa Agropecuária. Métodos analíticos físico-químicos para controle de leite e produtos lácteos. Instrução Normativa $\mathrm{n}^{\circ}$. 68, de 12 de dezembro de 2006. Brasília:

Ministério da Agricultura, 2006. Disponível em:

$<$ http://extranet.agricultura.gov.br/sislegisconsulta/

consultarLegislacao.do?operacao=visualizar\&id=17472> Acesso em: 09 de out. 2016.

BRASIL. Lei $n^{\circ} .11 .428$, de 22 de dezembro de 2006. Regime jurídico do bioma mata atlântica. Disponível em: <http:// www.planalto.gov.br/ccivil_03/_ato2004-2006/2006/ lei/l11428.htm>. Acesso em: $0 \overline{8}$ de out. 2016.
COLUSSI, J. Operação Leite Compen\$ado descobre ramificação da fraude do Paraná. Zero Hora, Porto Alegre, 11 jun. 2015. Disponível em: <http://zh.clicrbs.com.br/rs/ noticias/economia/noticia/2014/06/operacaoleite-compen-ado-descobre-ramificacao-dafraude-no-parana-4523785.html>. Acesso em: 25 de nov. 2015.

CORBUCCI, F.S.; GRASSI, T.L.M.; PONSANO, E.H.G. Ações para a melhoria da qualidade do leite. $8^{\circ}$ Congresso de Extensão Universitária da UNESP, 2015. Disponível em: http://200.145.6.205/index.php/ congressoextensao/8congressoextensao/paper/ viewFile/1594/272>. Acesso em: 09 de out. 2016.

FOOD AND AGRICULTURE ORGANIZATION OF THE UNITED NATIONS (FAO). Dairy production and products - milk production. Disponível em: <http:// www.fao.org/agriculture/dairy-gateway/milkproduction/en/\#.V3AZwbgrLIV>. Acesso em: 24 jul. 2017.

FROEHLICHI, J.M.; RAUBER, C.C.; CARPES, R.H. et al. Êxodo seletivo, masculinização e envelhecimento da população rural na região central do RS. Ciência Rural, Santa Maria, v.41, n.9, p.1674-1680, 2011.

GALVÃO, C.E. Qualidade do leite de vaca: microbiologia, resíduos químicos e aspectos de saúde pública. Universidade Castelo Branco. Monografia (Especialização em higiene e inspeção de produtos de origem animal), Campo Grande, 2009.

INSTITUTO BRASILEIRO DE GEOGRAFIA E ESTATÍSTICA - IBGE. Rio Grande do Sul - São Martinho: População. IBGE, 2010. Disponível em: <http://cidades.ibge.gov.br/xtras/ perfil.php?codmun=431910 $>$. Acesso em: 25 de nov. 2015.

JUNG, C.F.; MATTE J.R., A.A. Produção leiteira no Brasil e características da bovinocultura leiteira no Rio Grande do Sul. Ágora, v.19, n.01, p.34-47, 2017. 
LEITE BRASIL, CNA; OCB. et al. 19 Ranking maiores empresas de laticínios do Brasil - 2015. Disponível em: <http:// www.leitebrasil.org.br/ maiores\%20laticinios\%202015\%20final.pdf > . Acesso em: 09 de out. 2016.

LEONE, E.T.; MAIA, A.G.; BALTAR, P.E. Mudanças na composição das famílias e impactos sobre a redução da pobreza no Brasil.

Economia e Sociedade, Campinas, v.19, n.1(38), p.59-77, 2010.

MARTINS, E.O.; SANTOS, H.A.; VIANA, D.A.F. et al. Análise físico-química para a avaliação da qualidade do leite de propriedades localizadas na Região Norte do Estado de Sergipe. Scientia Plena, v.11, n.4, 2015.

MEDEIROS, F.M.; BRUM. A, L. O mercado do leite no rio grande do sul: Evolução e tendências. UNIJUI Universidade Regional do Noroeste do Estado do Rio Grande do Sul, 2016. Disponível em: http:// bibliodigital.unijui.edu.br:8080/xmlui/bitstream/ handle/123456789/3318/FL\%C3\%81VIO\%20-\%20 O\%20MERCADO\%20DO\%20LEITE\%20NO\%20RIO\% 20GRANDE\%20DO\%20SUL\%20-\%20EVOLU\%C3\% 87\%C3\%83O\%20E\%20TENDENCIAS.pdf?sequence $=1>$ Acesso em: 22 de nov. 2016.

MEZZADRI, F.P. Análise da conjuntura agropecuária leite - ano 2014. Secretaria de Estado da Agricultura e do Abastecimento. DERAL - Departamento de Economia Rural. Disponível em: < http://www.agricultura.pr.gov.br/ arquivos/File/deral/Prognosticos/

bovinocultura_leite_14_15.pdf > Acesso em: 30 de nov. 2016.

MILKPOINT. IBGE: produção de leite cresceu 2,7\% em 2014; Sul tornou-se a maior região produtora. Disponível em: $<$ www.milkpoint.com.br/cadeia-do-leite/giro-lacteo/ ibge-producao-de-leite-cresceu-27-em-2014-sultornouse-a-maior-regiao-produtora-97326n.aspx>. Acesso em: 30 de nov. 2016.
PAIXÃO, M.G.; LOPES, M.A.; PINTO, S.M. et al. Impacto econômico da implantação das boas práticas agropecuárias relacionadas com a qualidade do leite. Revista Ceres, Viçosa, v.61, n.5, 2014.

PARRÉ, J.L.; BÁNKUTI, S.M.S.; ZANMARIA, N.A. Perfil socioeconômico de produtores de leite da região sudoeste do paraná: um estudo a partir de diferentes níveis de produtividade. Revista de Economia e Agronegócio, v.9, n.2, 2011.

PINHEIRO, L.A.F. Deteç̧ão de fraude no leite com água pela capacidade térmica volumétrica. Dissertação (Mestrado Profissional em Ciência e Tecnologia do Leite e Derivados) - Universidade Federal de Juiz de Fora. Juiz de Fora Minas Gerais, 2015.

ROBIM, M.S.; CORTEZ, M.A.S.; SILVA, A.C.O. et al. Pesquisa de fraude no leite UAT integral comercializado no estado do Rio de Janeiro e comparação entre os métodos de análises físicoquímicas oficiais e o método de ultrassom. Revista do Instituto de Laticínios Cândido Tostes, v.67, n.389, p.43-50, 2012.

SENA, A.L.S.; SANTOS, M.A.S.; SANTOS, J.C. et al. Avaliação do nível tecnológico dos produtores de leite na região oeste do estado do Pará. Revista de Economia e

Agronegócio, v.10, n.3, p.397-418, 2013.

SILVA, C.I.; LOMBA, R.M.; FILOCREÃO, A.S.M. Assistência técnica e extensão rural na agricultura familiar do estado do Amapá. In: REENCONTRO DE SABERES TERRITORIALES LATINOAMERICANOS, 1 , Amapá. Brasil. 2013.

ZAGONEL, T.R.; TRENNPOHL; D.; AMARAL, V.R. et al. A cadeia produtiva do leite: discussões sobre a crise do setor lácteo na região celeiro do estado do Rio Grande do Sul. Revista da Universidade Vale do Rio Verde, v.14, n.2, p.191-205, 2016.

Recebido para publicação em 04/9/2017 e aprovado em 26/10/2017. 